\title{
A review of potential method for optimization of power plant expansion planning in Jawa-Madura-Bali electricity system
}

\author{
Rizki Firmansyah Setya Budi*, Sarjiya, Sasongko Pramono Hadi \\ Department of Electrical Engineering and Information Technology, Universitas Gadjah Mada, Jalan Grafika No. 2, Yogyakarta, 55281, Indonesia
}

Article history:

Received: 16 March 2017 / Received in revised form: 15 May 2017 / Accepted: 28 May 2017

\begin{abstract}
The paper contains a literature review to obtain an optimization method that potentially can be used to optimize power plant expansion of Jawa-Madura-Bali (Jamali) power system in 2015-2050. An optimization model that can represent auction process and direct appointment of IPP by considering the long term period (multi-period framework) and multi-objective function (economical, reliable, and environmentally friendly), is needed. Based on the literature review that has been done, it is obtained the method potentially can be used for Jamali system. The method is a game theory with multi-period, bi-level and multi-objective optimization method. Game theory is used to represent the auction process and direct appointment of IPP. Multi-period is used to represent the long term period from 2015-2050. Multi-objective optimization method is used to represent the aspects of cost, reliability, and $\mathrm{CO}_{2}$ emission which are considered in the optimization process
\end{abstract}

Keywords: optimization; expansion; power plant; Jamali

\section{Introduction}

PT. Perusahaan Listrik Negara (PLN) is an Indonesian government-owned corporation which is in charge of planning and implementing electricity projects in generation, transmission, and distribution sectors [1]. Transmission and distribution sectors are held entirely by PT. PLN. While generation sector, PT. PLN cooperate with the private sector in the form of rental generators or independent power producer (IPP) [1-6]. To support the task, PT. PLN has been planned the electrical system and published in Rencana Usaha Penyediaan Tenaga Listrik (RUPTL) 2015-2024. The book said that Indonesian electricity system is divided into 3 areas development plan: Sumatra electrical system, Java-MaduraBali (Jamali) electrical system, and Eastern Indonesia electrical system. Jamali power system is the largest system and has an important role in the growth of the national economy. Therefore, planning for a longer period of time is necessary in order to create sustainable planning based on national energy policy.

Figure 1 shows the projection of electricity sale in Indonesia. Jamali or JB has the biggest portion of Indonesia's electricity sale. In 2015 , the portion of Jamali's electricity sale is $75 \%$ and the portion in 2024 is $70 \%$ of Indonesia's electricity sale. The number of electricity sale is proportional to the power plant capacity. Therefore, a slight mistake in the power plant expansion planning will cause great losses. Planning errors can be caused by less optimized power plant optimization result and it is caused by local optimum value. To avoid the errors, it needs an optimization method that does not get stuck on the local optimum value.

* Corresponding author. Tel.: +62-856-4305-1287.

Email: rizki.firmansyah.s@mail.ugm.ac.id.

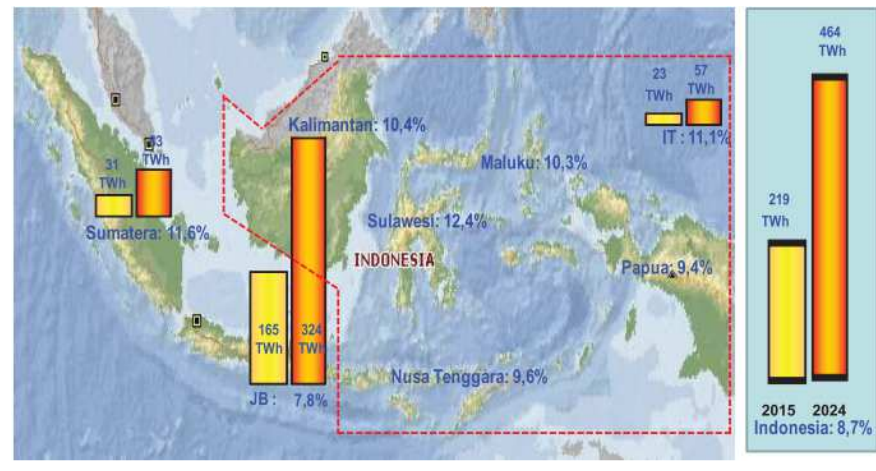

Fig.1. Projection of Indonesia's electricity sale [1]

IPP is a private power producer formed by the consortium to make a power purchase agreement (PPA) with PT. PLN and to develop, build, own, and operate the power plant. PPA is the electrical energy purchase agreement between IPP with PT. PLN [2]. The purchase process is divided into three kinds: direct appointment, direct selection, and open tender. The purchase price is the lowest price offered by IPP [2].

Statistics from PLN shows that the number of plants and the energy generated from IPP increases every year[3-5]. Figure 2 shows the electricity production in Indonesia. The electricity that is produced by IPP increases each year. The majority of IPP located in Jamali. This number will continue to increase in line with government policies that encourage the public sector to participate in the electricity sector development. The example of this policy is 35,000 MW power plant program, where 25,904 MW is planned to be built by IPP either with the direct appointment or open tender process [6]. Because of the PPA mechanism, the power plant expansion planning cannot be done using general optimization 
methods. General methods cannot present the open tender process.

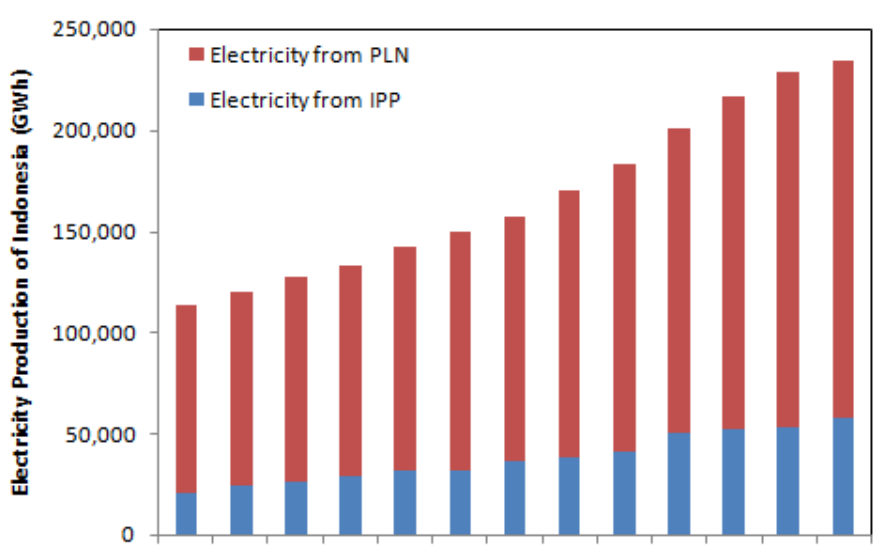

Fig. 2. Electricity Production of Indonesia [3-5,7,8]

The open tender process or auction process will make the electricity market to be deregulated electricity market. In this market, the electricity price depends on the competition of IPP companies $[9,10]$. It is mean that PT. PLN cannot set the electricity price from IPP companies. It is different from the regulated electricity market. In regulated electricity market, PT. PLN can set the price. The regulated electricity market only can be used for electricity from PLN's power plants. In the deregulated market, PT. PLN cannot know how much the electricity price from IPP. The lack of the price knowledge can make the power plant expansion planning not suitable with the fact. To solve the problem, a method can be used to represent auction process, so PT. PLN can make a good planning that optimal and suitable with the fact.

In addition to the economic factors, few factors that must be considered in the optimization process of power plant expansion are the reliability factor of the system and environmental factor especially for $\mathrm{CO}_{2}$ [11-16]. The reliability factor has been used in RUPTL is LOLP index [1]. With the consideration, it will make economical, reliable, and environmentally-friendly expansion plant. Therefore, a method of optimization expansion plant for Jamali power system that considering the economic factor, reliability factor, and environmental factor, is needed.

Several researches have been done power plant expansion planning in Jamali System using various methods. In the research [17], expansion planning in Jamali System has been done using linear programming with $\mathrm{CO}_{2}$ emission limit consideration. In linear programming, the optimal solution is sought by using all alternative combinations of existing solutions. The objective function is least cost, while $\mathrm{CO}_{2}$ emission is used as a limitation. The method used in research [17] cannot be used for multi-objective function and cannot represent the auction process. The method cannot represent the auction process because the optimal solution is obtained without considering the interest of IPP companies to maximize their profit.

Research [18,19] has been done power plant expansion planning in Jamali System using mathematical modeling analysis. The objective functions are minimizing generation cost and minimizing $\mathrm{CO}_{2}$ emission. The optimal solution is obtained based on the minimal value of the objective functions in each alternative solution without considering the objective function of each power plant in the alternative solution. It shows that the model used in research $[18,19]$ cannot represent the auction process.

Research [20-24] have been planning the power plants expansion in Jamali System using long-range energy alternatives planning (LEAP) software. Optimization in the software is based on linear programming. The objective function is least cost. Linear programming in LEAP software cannot be used to represent the auction process. The least cost objective function cannot be used for an objective function that cannot be brought to the value of money, such as LOLP index.

Based on the research [17-24], it can be seen that the optimization methods used in Jamali System cannot be used for deregulated markets so it is not suitable for the IPP expansion that used auction process. Several methods have been used for two objective functions: generation cost and $\mathrm{CO}_{2}$ emission. These researches have not yet used the LOLP index as a reliability objective function.

To fulfill the requirement of Jamali optimization planning, a method that could represent a direct appointment or open tender process while considering the economic factor, reliability factor, and environmental factor, is needed. The purpose of this study is to get a new method that potentially can be used in power plant expansion and obtaining the optimal composition of power plant in Jamali System from the year 2015 to 2050 . The variables that determine the optimal composition of power generation capacity are the minimum cost, minimum $\mathrm{CO}_{2}$ emissions, and maximum system reliability. The method should be able to represent the auction process, can be used for multi-objective functions, and do not get stuck at the local optimum value.

\section{The Use of Various Methods in Power Plant Expansion Optimization}

Several methods have been used in the optimization of expansion plants, such as genetic algorithm, differential evolution, evolutionary programming, evolutionary strategy, particle swarm optimization, tabu search, simulated annealing, hybrid approach, and game theory.

\subsection{Genetic Algorithm}

Genetic algorithm (GA) is a search algorithm to get an optimum point by imitating the process of genetics and natural selection. The parameters that determine the optimum point accuracy on GA are crossover and mutation [25]. The values of these parameters will affect the results of the optimization. GA has been widely used in power plant expansion optimization process [26-34]. GA uses a stochastic approach so it can produce a relatively faster computing [33]. However, the conventional GA models have the disadvantage of premature convergence and duplication population [26]. To solve these problems, research [33] made GA development.

The developments in [33] are to manufacture artificial scheme for the determination of the initial population and make stochastic crossover strategy. The method used in [33] is called Improved Genetic Algorithm (IGA).

IGA use a single objective function and bi-level optimization method. The objective function is a cost function (operating cost, investment cost, and salvage value). The bilevel optimization method is used by selecting the alternative solutions that meet the requirements of LOLP index. The alternative solutions are optimized by IGA. Objective function 
value in IGA is calculated for each set of the solution which consists of several plants that will be developed.

The result of [33] showed that the optimum point accuracy still depends on the determination of crossover and mutation probability. IGA produces optimum value better than conventional GA, but it is still possible to get stuck in a local optimum value. To get the best results, it takes a few tries to obtain the most optimal parameter values.

\subsection{Differential Evolution}

Based on the principle works, differential evolution (DE) is almost same as GA, which applies the principle of natural selection and evolution to find the optimum value. The difference is GA mutations occur randomly, while DE mutation process is determined by the value of constant F. DE mutation follows equation (1) $[25,35,36]$,

$$
V_{i, j+l}=X_{r 5, j}+F\left(X_{r 1, j}-X_{r 2, j}+X_{r 3, j}-X_{r 4, j}\right)
$$

where $V_{i, j+1}$ is $i^{\text {th }}$ individual that has a mutation and use for next iteration; $X_{r 5}, X_{r 1}, X_{r 2}, X_{r 3}$, and $X_{r 4}$ are random individuals from the current population; and $F$ is the constant value that determines the mutation.

After the mutation process, the crossover has been done based on the value of crossover rate (CR)[25,37]. The crossover process follows equation (2) $[25,35,36]$.

$$
U_{i, j+1}=X_{i, j} x(1-C R)+V_{i, j+1} x C R
$$

where $X_{i, j}$ is $i^{\text {th }}$ individual from the current population; $U_{i, j+1}$ is $i^{t h}$ individual that has crossover and use for next iteration; and $C R$ is the crossover rate. $F$ and $C R$ determine the fitness function value of the population.

Determining the value of $F$ and $C R$ will affect the optimum value accuracy. Objective function value in DE is calculated for each set of the solution which consists of several plants that will be developed.

Except for the mutation process and crossover, the methods applied in IGA can be applied also in DE. The results of [25,35-37] showed that the optimization results using DE still has a possibility to get stuck in a local optimum value. The value of optimal solution depends on population size, mutation value, and crossover rate. To get the best result need to take several simulations and using different population size, mutation value, and crossover rate in each simulation to obtain the most optimal different population size, mutation value, and crossover rate.

\subsection{Evolutionary Programming}

Evolutionary programming (EP) is an optimization technique that based on mutation mechanism and competitive selection. Mutation mechanism and competitive selection are represented by the offspring (Off). The offspring calculation follows equation (3) [25,38,39].

$$
\begin{gathered}
O f f_{i, j}=P_{i, j}+N(O, \sigma) \\
\sigma=\beta \cdot \gamma \cdot\left(X_{\max , j}-X_{\min , j}\right) \\
\gamma=f_{i} / f_{\text {min }}
\end{gathered}
$$

where $O f f_{i, j}$ is the $j^{\text {th }}$ component of the $i^{\text {th }}$ offspring; $P_{i, j}$ is the $j^{\text {th }}$ component of the $i^{\text {th }}$ parent; $N(0, \sigma)$ is a random value with zero mean and standard deviation $\sigma$. The standard deviation calculates using equation (4). $\beta$ is a constant value ( 0 or 1$)$.
$X_{\max , j}$ is the maximum value of $j^{\text {th }}$ individuals. $X_{\min , j}$ is the minimum value of $j^{\text {th }}$ individuals. $\gamma$ is the correction factor to make a better mutation effect. The correction factor calculates using equation (5). $f_{i}$ is the $i^{\text {th }}$ parent objective function. $f_{\min }$ is the minimum objective function among all the parents.

The mutation mechanism is done by considering the standard deviation of all individual fitness function from the previous generation (parents). Besides the standard deviation, the correction factor of mutation effect is used also to improve the accuracy of optimization result [25]. Using standard deviation and correction factor, the competitive selection process conducted. The best individual will be used for the next iteration. Objective function value in EP is calculated for each set of the solution which consists of several plants that will be developed.

The standard deviation and correction factor determine the objective function of population. Those factors depend on the value of $\sigma$ and the population size. Determining the value of $\sigma$ and the population size will affect the optimum value accuracy. Objective function value in EP is calculated for each set of the solution which consists of several plants that will be developed.

The EP difference with the previous method lies in the mutation process and the absence of crossover process. Except for those, the methods used in IGA can be used in this method. The results of $[25,32,38,39]$ showed that the optimization results using EP still has a possibility to get stuck in a local optimum value. To get the best result needs to take several simulations by using different population size and standard deviation in each simulation to obtain the most optimal population size and standard deviation $\sigma$.

\subsection{Evolutionary Strategy}

Evolutionary strategy (ES) is an evolutionary computation technique using mutation index with a predetermined value. The mutation index is represented by the offspring (Off). The offspring calculates using equation (6).

$$
O f f_{i, j}=P_{i, j}+N(0, \nabla)
$$

where $O f f_{i, j}$ is the $j^{\text {th }}$ component of the $i^{\text {th }}$ offspring; $P_{i, j}$ is the $j^{\text {th }}$ component of the $i^{\text {th }}$ parent; $N(0, \nabla)$ is a random value with zero mean and standard deviation $\nabla . \nabla$ is the constant value.

The value of $\nabla$ determines based on the ongoing optimization condition [25]. For example, if after five iterations the objective function value does not change, the value of $\nabla$ will be made into maximum value, whereas if there is a change in the objective function value, the $\nabla$ will be half. Objective function value in ES is calculated for each set of the solution which consists of several plants that will be developed.

Optimization process in this method is similar to EP. The difference lies in the mechanism of mutation rate determination that is used. Except for the mutation process, all methods in EP can be used also in ES.

The results of [25,32] showed that the optimization results using ES still has a possibility to get stuck in a local optimum value. To get the best result needs to take several simulations by using different population size and $\nabla$ in each simulation to obtain the most optimal population size and $\nabla$.

\subsection{Particle Swarm Optimization}

Particle swarm optimization (PSO) is an optimization technique that mimics the movement of a few birds in the 
absence of collisions between individuals within the flock $[25,40,41]$. Each of iteration will produce the best flock value and the best individual value in each flock. Both of these values will be used for the next iteration to obtain the desired optimization value. Objective function value in PSO is calculated for each set of the solution which consists of several plants that will be developed. Optimization using PSO follows equation (7)-(9) [25,42,43].

$$
\begin{gathered}
v_{i}^{k+1}=w v_{i}^{k}+C_{1} \operatorname{rand}_{1}\left(p_{\text {best }}-s_{i}^{k}\right)+C_{2} \text { rand }_{2} \\
\left(g_{\text {best }}-s_{i}^{k}\right) \\
w=w_{\text {max }}-\left(\left(w_{\text {max }}-w_{\text {min }}\right) / \text { iter }_{\text {max }}\right) \text { iter } \\
s_{i}^{k+1}=s_{i}^{k}+v_{i}^{k+1}
\end{gathered}
$$

where $v_{i}^{k+1}$ is $i^{\text {th }}$ individual velocity at $(k+1)^{\text {th }}$ iteration; $w$ is the weight; $v_{i}^{k}$ is $i^{\text {th }}$ individual velocity at $k^{\text {th }}$ iteration; $C_{l}$ and $C_{2}$ are the positive constants; $p_{\text {best }}$ is the $i^{\text {th }}$ individual best position; $g_{\text {best }}$ is the group best position; $s_{i}^{k}$ is the $i^{\text {th }}$ individual position at $k^{\text {th }}$ iteration; $w_{\max }$ is the initial weight; $w_{\min }$ is the final weight; iter is the current iteration number; iter $_{\max }$ is the max. iteration number; and rand $_{1}$, rand $_{2}$ are random number.

From the equation can be known that this method uses a stochastic approach. Parameters that influence the optimization results accuracy in this method are the maximum weighting factor $\left(\mathrm{W}_{\max }\right)$, the minimum weighting factor $\left(\mathrm{W}_{\text {min }}\right)$, positive constant $1\left(\mathrm{C}_{1}\right)$, and positive constant $\left(\mathrm{C}_{2}\right)$. These parameters will affect the speed value of each individual and the optimum value of each individual. Based on the location of each individual, its optimum value can be obtained which will be used for the next iteration.

The results of $[25,42,43]$ showed that the optimization results using PSO still has a possibility to get stuck in a local optimum value. To get the best result need to take several simulations and using $W_{\max }, W_{\min }, C_{1}$ and $C_{2}$ in each simulation to obtain the most optimal value.

\subsection{Tabu Search}

Tabu search (TS) is an optimization method by using the value of its neighbors search procedure [25]. The set of neighbor's objective function value will be compared to objective function value of the original individual. The individual was taken and used for the next iteration is the individual who has the best objective function. Objective function value in TS is calculated for each set of the solution which consists of several plants that will be developed.

The parameters that determine the optimization accuracy is the number of individual neighbors that is used $(\mathrm{N})$. This number will affect the areas that will be seen as a comparison. Tabu list is used to record the optimization results obtained in several iterations. It does not affect the optimization accuracy in [25] because individual neighbors were randomly generated without following a particular scheme.

The results of [25,44-46] showed that the optimization results using TS still has a possibility to get stuck in a local optimum value. To get the best result need to take several simulations and using a different number of individual neighbors and tabu list in each simulation to obtain the most optimal value.

\subsection{Game Theory}

Game theory (GT) is a mathematical model that is used for decision-making in the event of a conflict of interest among many players. Game theory involves more than one player who influences each other [47]. The optimum condition occurs when Nash equilibrium is created. Nash equilibrium occurs when each player does not change his decision. This happens because each player had to get the maximum benefit when Nash equilibrium existed, so when a player changes his decision, it does not benefit anymore [48].

The value of the objective function in GT is calculated for each power plant, unlike the previous methods that calculate a set of solutions which consists of several power plants. GT calculates the objective function for any possible solution that existed. This computation is similar to the computing process in dynamic programming so it does not get stuck in a local optimum value.

GT has been widely used in the optimization process of power plant expansion [49-59]. GT can be used for optimization process of power plant expansion by imitating the auction process $[60,61]$. Each power plant will be given a payoff value used to determine the optimal composition of the power plants. The power plant composition that has the great payoff value will be used as an optimal solution.

Bi-level model has been used in GT for the development power plant by paying particular attention to the influence of transmission line, investment cost competition, the uncertainty of electrical demand, and uncertainty of player's offers [4951,53-55]. Probabilistic dynamic programming model has been used in GT to solve the problem of investment cost by considering the uncertainty of electrical demand [52]. Hybrid dynamic programming/game framework has been used in [56] to solve the problems of investment in power plant development. In the work [56], Cournot game used to model the strategies of power producers in the spot market. The research [57] using multi-period framework for power plant development by considering the uncertainty of electricity market. Problems of investment in [57] are modeled as a bilevel optimization problem.

\subsection{Multi-Objective Fractional Programming Method}

Multi-objective fractional programming method (MOFPM) is used to optimize using more than one objective function that has conflict. The objective function problem can be resolved by fractional programming. Objective function value in MOFPM is calculated for each set of the solution which consists of several plants that will be developed.

Research [58,62-66] have used some objective function in power plant development, such as: minimize cost, minimize the negative impact to the environment, maximize system reliability, and minimize the number of import fuels. Research [67] have used three objective problems in power plant development. The objective functions are maximizing the energy generation, minimizing $\mathrm{CO} 2$ emission, and minimizing costs. The method in [67] is to transform the multi-objective problem into a single objective problem by using linearization and parameterization approach.

Fractional programming will change multi-objective function into a single objective function by using Dinklebach's theorem and Guzel's approach. The multiobjective function change into a single objective function by using equation (10).

$$
\operatorname{Max} F=N x, D x \rightarrow \operatorname{Max} F=N x / D x
$$

$N x$ is the maximum optimization function and $D x$ is the minimum optimization function. Based on Dinklebach's theorem and Guzel's approach, it can be obtained the maximum value of $F$ occurs at maximum $N x / D x$ [68]. 


\section{Potential Method for Optimization of Power Plant Expansion in Jawa-Madura-Bali Power System}

Based on the literature review on the use of various methods in the optimization of power plant development, can take several points as shown in Table 1. Each method has different characteristics. Based on the characteristics comparison, the potential method can be chosen.

The use of stochastic approach in the optimization process will affect the optimization accuracy. Optimization accuracy is identical with the optimization result that is trapped in local optimum value or not. In other words, the optimization result is not the actual optimum value. The optimization accuracy using a stochastic method is affected by the determination of the parameter values.

Jamali System is the biggest interconnection power system in Indonesia which has installed capacity $32,3 \mathrm{GW}$ and energy production $188 \mathrm{GWh}$ in 2015 . These made the Jamali system requires an optimization method that is not trapped in local optimum value and does not depend on the determination of the parameters, so the actual optimum value can be obtained. If the optimization is stuck at the local optimum value and makes the generation cost increase Rp. $1 / \mathrm{kWh}$, it will make loss about Rp 188 million/year (188 GWh x Rp. 1/kWh).
To avoid the loss, the optimization method that calculates the objective function value for all available possibilities is required. Counting process for each of these possibilities is same as in the dynamic programming process.

The weaknesses of dynamic programming calculation, especially in a large system such as Jamali system was on a long computation time. However, development power plant in Jamali system is a long-term planning that does not need fast respond computation, so the long computing time can be tolerated. Table 1 shows that the methods using dynamic programming principle are game theory and MOFPM.

A method that can represent the auction process is required in the optimization power plant development in Jamali system. This relates to the electricity purchase process from IPP in Jamali System. To represent the auction process of electricity purchase from IPP in Jamali System, the method should calculate the objective function of each power plant unit, not on a set of combinations of power plants. Objective function calculations on each plant will make the optimization process can be performed on each power plant unit. The process to find the optimum point on each power plant, use Nash equilibrium. Table 1 shows the method can represent the auction process is game theory.

Table 1. Characteristics Comparison of Each Optimization Methods

\begin{tabular}{|c|c|c|c|c|c|c|c|c|}
\hline Characteristics & IGA & $\mathrm{DE}$ & $\mathrm{EP}$ & ES & PSO & $\mathrm{TS}$ & GT & MOFPM \\
\hline Using stochastic approach & Yes & Yes & Yes & Yes & Yes & Yes & No & No \\
\hline Calculates objective function value for all possibilities & No & No & No & No & No & No & Yes & Yes \\
\hline Can represent the auction process or not & No & No & No & No & No & No & Yes & No \\
\hline Multiobjective function & No & No & No & No & No & No & Yes & Yes \\
\hline Single objective function & Yes & Yes & Yes & Yes & Yes & Yes & Yes & Yes \\
\hline Bi-level optimization method & Yes & Yes & Yes & Yes & Yes & Yes & Yes & Yes \\
\hline
\end{tabular}

Using optimization methods that cannot represent the auction process (IGA, DE, EP, ES, PSO, TS, and MOFPM) will cause errors in financial planning of PT. PLN. Without taking account the interest factor of IPP companies to get the maximum profit, it will cause the planning is not appropriate. For example, PT. PLN has planned to build $50 \mathrm{MW}$ wind power plant in Samas Beach Yogyakarta. The wind power plant will be built by private parties and will operate in 2014 [69]. However, until 2017, the wind power plant has not been built. Then the planning to build the wind power plant was revised to 2018 or 2019 [1,70]. Until now, the process to build wind power plant in Samas is not started yet. In addition to the wind power plant, there are many other power plants that withdrawn from the plan and re-scheduled. This is because the private parties are less interest to invest. The non-conformity of the plan with the fact is because the expansion planning does not take into account the interest factor of IPP companies. By using the game theory that takes into account the interest factor of IPP companies, it will get the expansion planning more precise, especially in IPP expansion planning.

The method that can solve multi-objective function is needed to resolve the problems caused by economic, reliability, and environmental objective function. Based on Table 1, the methods can be used are game theory and MOFPM. In MOFPM, there are steps to change multiobjective function into a single objective function by using fractional programming. The steps can be used also for other methods that are still using a single objective function. In other words, the addition of fractional programming in the objective function calculation will make each method can be used for multi-objective function. Thus, all of the methods listed in Table 1 can be used in optimization process of Jamali system.

The bi-level optimization method is required in optimization process of Jamali system because economic objective function (profit) is a maximum optimization, environment objective function $\left(\mathrm{CO}_{2}\right.$ emission) is a minimum optimization, and reliability objective function is limitation function. Economic and environment objective function can be combined into a single objective function by using fractional programming. While reliability objective function cannot be combined because it is a limitation function. Bilevel optimization method works with the following principles:

At the first level, the optimization process is carried out by using reliability objective function. The LOLP standard in Jamali System is $\leq 0,274 \%$. Each solution set of power plant combinations that have LOLP index $\leq 0,274 \%$ will be put into the matrix of alternatives solution. The process is carried out for all combination.

- At the second level, the optimization process is carried by using economic and environmental objective functions that performed on the alternatives solution matrix. The objective function is calculated for each power plant unit.

Based on Table 1, each method in the table can be used for the bi-level optimization process. 
By using multi-objective function and bi-level method, it will get the power plant expansion planning of Jamali System which is in line with Indonesia National Energy Policy. In the policy, it is mandated to make an expansion planning that considers economic, reliability, and environmental factor [71].

Based on the comparative analysis of the optimization method characteristics and the needs of Jamali system, game theory and its development is the potential method to be used in optimization of power plant expansion planning in Jamali system. Using these methods, the problems in Jamali system optimization can be solved and the purposes can be achieved.

The development of game theory is done by adding multiobjective function, bi-level method, and multi-period framework. The multi-period framework is required to undertake a long-term planning.

Research [48] show that the main problem using game theory for power plant expansion planning is at computation time. The computation time will increase significantly as the number of power plants and the number of strategies increase. In addition, for power systems that have a very large number of power plants, the calculation of LOLP index will take a long time. It caused by the COPT matrix [72,73].

Jamali System has 98 unit existing power plants and 8 types power plant candidates for expansion planning [1]. With the huge number of power plants, the time required for optimization by using game theory will be long, so it needs a method that can be used to speed up the computing time. Therefore, future research will focus on accelerating computing time or decrease the complexity of the computation, especially in the process to find nash equilibrium and COPT matrix.

\section{Conclusion}

Jamali power system is the biggest inter-connection power system in Indonesia. These made the Jamali system requires an optimization method that is not trapped in local optimum value. In the power plant planning, PLN increases the portion of IPP's power plant either with the direct appointment or open tender process. PLN considers the economic factor, reliability factor, and environmental factor in the optimization of Jamali's power plant. Therefore, a method of optimization expansion plant for Jamali power system that could represent a direct appointment or open tender process while considering the economic factor, reliability factor, and environmental factor, is needed. Game theory can potentially be used for optimization of power plant expansion planning in Jamali system because it has characteristics: can represent auction process and can be used for multi-objective optimization. Development of the method is necessary in order to achieve optimization purposes. This development is done by adding a multi-period framework, bi-level optimization method, and multi-objective optimization method.

\section{Acknowledgements}

The author would like to thank Dr. Eka Firmansyah and Badan Tenaga Nuklir Nasional (BATAN) for the support.

\section{References}

1. PT PLN. Rencana Usaha Penyediaan Tenaga Listrik (RUPTL) PT. PLN
(Pesero) 2015-2024. Jakarta: PT. PLN, 2014.

2. PT PLN. Buku IPP. Jakarta: PT. PLN, 2015

3. PT PLN. Statistik PLN 2011. Jakarta: PT. PLN, 2011.

4. PT PLN. Statistik PLN 2012. Jakarta: PT. PLN, 2012.

5. PT PLN. Statistik PLN 2013. Jakarta: PT. PLN, 2013.

6. PT PLN. 35.000 MW untuk Indonesia. Jakarta: PT PLN, 2015.

7. PT PLN. Statistik PLN 2014. Jakarta: PT. PLN, 2015.

8. PT PLN. Statistik PLN 2015. Jakarta: PT. PLN, 2016.

9. K. K. Nargale and S. B. Patil, Day Ahead Price Forecasting in deregulated electricity market using artificial neural network, International Conference on Energy Efficient Technologies for Sustainability (ICEETS), 2016, pp. 527-532.

10. K. S. Ahmed and S. P. Karthikeyan, Proportional generation and proportional load based approach for transmission loss / cost allocation in deregulated electricity market, Region 10 Conference (TENCON), 2016, pp. 723-725.

11. P. Rocha, T. K. Das, V. Nanduri, and A. Botterud, Impact of $\mathrm{CO}_{2}$ capand-trade programs on restructured power markets with generation capacity investments, Int. J. Electr. Power Energy Syst. 71 (2015) 195208.

12. M. Benidris, S. Elsaiah, and J. Mitra, Electrical power and energy systems an emission-constrained approach to power system expansion planning, Int. J. Electr. Power Energy Syst. 81 (2016) 78-86.

13. S. Rebennack, Generation expansion planning under uncertainty with emissions quotas, Electr. Power Syst. Res. 114 (2014) 78-85.

14. J. Aghaei, M. A. Akbari, A. Roosta, and A. Baharvandi, Multiobjective generation expansion planning considering power system adequacy, Electr. Power Syst. Res. 102 (2013) 8-19.

15. S. M. M. Tafreshi, A. S. Lahiji, J. Aghaei, and A. Rabiee, Reliable generation expansion planning in pool market considering power system security, Energy Convers. Manag. 54(1) (2012) 162-168.

16. N. Anglani and G. Muliere, Analyzing the impact of renewable energy technologies by means of optimal energy planning tools for the energy management of local and imported resources, International Conference on Environment and Electrical Engineering (EEEIC), 2010, pp. 1-5.

17. Farizal, W. E. Septia, A. Rachman, Nasruddin, and T. M. I. Mahlia, Optimization of electricity generation schemes in the Java-Bali grid system with $\mathrm{CO}_{2}$ reduction consideration, Makara J. Technol. 20(2) (2016) 49-57.

18. M. T. Sambodo, Mathematical modeling analysis for investigating the future expansion of the electric power, Masy. Indones. 39(1) (2014) 193214.

19. M. T. Sambodo, H. Morohosi, and T. Oyama, Modeling power plant expansion in Java-Bali System: Evaluating minimizing cost and minimizing $\mathrm{CO}_{2}$ emissions, 3rd International Association for Energy Economics (IAEE) Asian Conference, 2012, pp. 20-22.

20. R. A. Al Hasibi, S. P. Hadi, and A. N. Widiastuti, Optimizing geothermal energy and hydro power in capacity expansion at the electrical system of Java-Madura-Bali, Int. J. Eng. Comput. Sci. IJECS-IJENS 13(1) (2013) $1-8$.

21. Y. Tanoto and M. E. Wijaya, Nuclear power plant development in JavaMadura- Bali area: The Indonesian long-term electricity planning perspective, Int. J. Energy Eng. 2(2) (2012) 32-35.

22. M. E. Wijaya and B. Limmeechokchai, Optimization of Indonesian geothermal energy resources for future clean electricity supply: A case of Java-Madura-Bali system, Int. J. Renew. Energy 4(2) (2009) 13-24.

23. M. E. Wijaya and B. Limmeechokchai, Supply Security Improvement of long term electricity expansion planning of Java-Madura-Bali system in Indonesia, Thammasat Int. J. Sc. Tech. 14(4) (2009) 47-59.

24. Y. Tanoto and M. E. Wijaya, Economic and environmental emissions 
analysis in Indonesian electricity expansion planning : Low-rank coal and geothermal energy utilization scenarios, 2011 IEEE First Conference on Clean Energy and Technology (CET), 2011, pp. 177-181.

25. S. Kannan, S. M. R. Slochanal, S. Baskar, and P. Murugan, Application and comparison of metaheuristic techniques to generation expansion planning in the partially deregulated environment, IET Gener. Transm. Distrib. 1(1) (2007) 111-118.

26. D. E. Goldberg. Genetic Algorithms in Search, Optimization, and Machine Learning. Alabama: Addison-Wesley Publishing Company, Inc., 1989

27. D. C. Walters and G. B. Sheble, Genetic algorithm solution of economic dispatch with valve point loading, IEEE Trans. Power Syst. 8(3) (1993) 1325-1332.

28. P. H. Chen and H. C. Chang, Large-scale economic dispatch by genetic algorithm, IEEE Trans. Power Syst. 10(4) (1995) 1919-1926.

29. D. R. Mcgregor, Thermal unit commitment using genetic algorithms, IEE Proceedings-Generation Transm. Distrib. 141(5) (1994) 459-465.

30. G. B. Sheblé, T. T. Maifeld, K. Brittig, G. Fahd, and S. FukurozakiCoppinger, Unit commitment by genetic algorithm with penalty methods and a comparison of Lagrangian search and genetic algorithm-economic dispatch example, Int. J. Electr. Power Energy Syst. 18(6) (1996) 339346.

31. K. Iba, Reactive power optimization by genetic algorithm, IEEE Trans. Power Syst. 9(2) (1994) 685-692.

32. K. Y. Lee and F. F. Yang, Optimal reactive power planning using evolutionary algorithms: a comparative study for evolutionary programming, evolutionary strategy, genetic algorithm, and linear programming, Power Syst. IEEE Trans. 13(1) (1998) 101-108.

33. J.-B. Park, Y.-M. Park, J.-R. Won, and K. Y. Lee, An improved genetic algorithm for generation expansion planning, IEEE Trans. Power Syst. 15(3) (2000) 916-22.

34. K. Y. Lee, X. Bai, and Y.-M. Park, Optimization method for reactive power planning by using a modified simple genetic algorithm, IEEE Trans. Power Syst. 10(4) (1995) 1843-1850.

35. A. Chandra, Role of mutation strategies of differential evolution algorithm in designing hardware efficient multiplier-less low-pass FIR Filter, J. Multimed. 7(5) (2012) 353-363.

36. S. Das and P. N. Suganthan, Differential evolution: A Survey of the state of the art, IEEE Trans. Evol. Comput. 15(1) (2011) 4-31.

37. A. Bhuvanesh, K. Karunanithi, and S. Kannan, Least cost generation expansion planning with wind power plant using differential evolution algorithm, International Conference on Circuit, Power and Computing Technologies [ICCPCT], 2014, pp. 540-547.

38. Y. Park, J. Won, J. Park, and D. Kim, Generation expansion planning based on an advanced evolutionary programming, IEEE Trans. Power Syst. 14(1) (1999) 299-305.

39. J. L. C. Meza, M. B. Yildirim, and A. S. M. Masud, A Multiobjective evolutionary programming algorithm and its applications to power generation expansion planning, IEEE Transactions On Systems, Man, Cybernetics_-Part A: Syst. Humans 39(5) (2009) 1086-1096.

40. F. J. Ruiz-Rodriguez, M. GOmez-Gonzales, and F. Jurado, Location of small-scale biomass based energy systems using probabilistic load flow and metaheuristic techniques, IEEE International Conference on Power System Technology (POWERCON), 2012, pp. 1-6.

41. X. Su, M. A. S. Masoum, and P. Woles, PSO based Multi-objective optimization of unbalanced Lv distribution network by PV Inverter, China International Conference on Electricity Distribution (CICED), 2014, pp. 1744-1748.

42. S. Kannan, S. M. Raja, P. Subbaraj, and N. P. Padhy, Application of particle swarm optimization technique and its variants to generation expansion planning problem, Electr. Power Syst. Res. 70 (2004) 203210.

43. C. Debao and Z. Chunxia, Particle swarm optimization with adaptive population size and its application, Appl. Soft Comput. 9 (2009) 39-48.

44. F. Wen and C. S. Chang, Transmission network optimal planning using the Tabu search method, Electr. Power Syst. Res. 42 (1997) 153-163.

45. M. H. Mashinchi, M. A. Orgun, and W. Pedrycz, Hybrid optimization with improved Tabu search, Appl. Soft Comput. 11 (2011) 1993-2006.

46. A. Sadegheih and P. R. Drake, System network planning expansion using mathematical programming, genetic algorithms and Tabu search, Energy Convers. Manag. 49 (2008) 1557-1566.

47. T. L. Turocy, B. Von Stengel, and B. von Stengel. Game theory. CDAM Research Report, 2001.

48. B. Chatterjee, An optimization formulation to compute Nash equilibrium in finite games, 2009 Proceeding of International Conference on Methods and Models in Computer Science (ICM2CS), 2009, pp 1-5.

49. P. Kaymaz, J. Valenzuela, and C. S. Park, Transmission congestion and competition on power generation expansion, IEEE Trans. Power Syst. 22(1) (2007) 156-163.

50. S. J. Kazempour, A. J. Conejo, and C. Ruiz, Generation investment equilibria with strategic producers-Part I: Formulation, IEEE Trans. Power Syst. 28(3) (2013) 2613-2622.

51. S. J. Kazempour, S. Member, A. J. Conejo, and C. Ruiz, Generation investment equilibria with strategic producers - Part II : Case Studies, IEEE Trans. Power Syst. 28(3) (2013) 2623-2631.

52. A. Botterud, M. D. Ilic, and I. Wangensteen, Optimal investments in power generation under centralized and decentralized decision making, IEEE Trans. Power Syst. 20(1) (2005) 254-263.

53. C. Ruiz and A. J. Conejo, Pool strategy of a producer with endogenous formation of locational marginal prices, IEEE Trans. Power Syst. 24(4) (2009) 1855-1866.

54. S. J. Kazempour, A. J. Conejo, and C. Ruiz, Strategic generation investment using a complementarity approach, IEEE Trans. Power Syst. 26(2) (2011) 940-948.

55. S. J. Kazempour and A. J. Conejo, Strategic generation investment under uncertainty via Benders decomposition, IEEE Trans. Power Syst. 27(1) (2012) 424-432.

56. T. Barforoushi, M. P. Moghaddam, M. H. Javidi, and M. K. Sheikh-ElEslami, Evaluation of regulatory impacts on dynamic behavior of investments in electricity markets: A new hybrid DP/GAME framework, IEEE Trans. Power Syst. 25(4) (2010) 1978-1986.

57. J. Valinejad and T. Barforoushi, Generation expansion planning in electricity markets: A novel framework based on dynamic stochastic MPEC, Int. J. Electr. Power Energy Syst. 70 (2015) 108-117.

58. A. S. M. Masud and M. B. Yildirim, Three multiple criteria models for power generation expansion planning: A review, Manuf. Eng. 1(1) (2012) 1146-1151.

59. W. Liu, J. Liu, M. Cui, and M. He, An introductory review on quantum game theory, 4th Int. Conf. Genet. Evol. Comput. ICGEC 2010, pp. 386389.

60. A. S. Chuang, F. Wu, and P. Varaiya, A game-theoretic model for generation expansion planning: Problem formulation and numerical comparisons, IEEE Trans. Power Syst. 16(4) (2001) 885-891.

61. S. Kamalinia, M. Shahidehpour, and L. Wu, Sustainable resource planning in energy markets, Appl. Energy 133 (2014) 112-120.

62. C. H. Antunes, A. G. Martins, and I. S. Brito, A multiple objective mixed integer linear programming model for power generation expansion planning, Energy 29(4) (2004) 613-627.

63. Y.-C. Kim and B.-H. Ahn, Multicriteria generation-expansion planning with global environmental considerations, IEEE Trans. Eng. Manag. 
40(2) (1993) 154-161

64. V. Kalika and S. Frant, Methodology of power generation system planning: multicriteria optimization accounting for uncertainty factors, 19th Convention of Electrical and Electronics Engineers, 1996, pp. 9193.

65. Q. Hu, G. H. Huang, Y. P. Cai, and W. Sun, Planning of electric power generation systems under multiple uncertainties and constraint-violation levels, J. Environ. Informatics 23(1) (2014) 55-64.

66. J. L. C. Meza, M. B. Yildirim, and A. S. M. Masud, A model for the multiperiod multiobjective power generation expansion problem, IEEE Trans. Power Syst. 22(2) (2007) 871-878.

67. F. Chen, G. Huang, and Y. Fan, A linearization and parameterization approach to tri-objective linear programming problems for power generation expansion planning, Energy 87 (2015) 240-250.

68. N. Güzel, A proposal to the solution of multiobjective linear fractional programming problem, Abstr. Appl. Anal. 2013 (2013) 1-4.

69. PT PLN. Rencana Usaha Penyediaan Tenaga Listrik PT PLN (Pesero) 2012-2021. Jakarta: PT. PLN, 2012.

70. PT PLN. Rencana Usaha Penyediaan Tenaga Listrik PT PLN (Pesero) 2016-2025. Jakarta: PT. PLN, 2016.

71. Peraturan Pemerintah Republik Indonesia Nomor 79 Tahun 2014 tentang Kebijakan Energi Nasional. Jakarta, 2014.

72. A. Kumar, S. Sehgal, D. Arora, and A. Soni, Capacity outage probability table calculation (COPT) of Haryana power generation corporation limited using VBA, Int. J. Tech. Res. 2(2) (2013) 6-11.

73. R. C. G. II, L. Wang, M. Alam, C. Singh, S. Shekara, and S. Reddy, An examination of artificial immune system optimization in intelligent state space pruning for LOLP estimation, North American Power Symposium (NAPS), 2011, pp. 1-7. 